\title{
A DESCENTRALIZAÇÃO DA POLÍTICA NACIONAL DE ATER: UMA EXPERIÊNCIA NOS ASSENTAMENTOS DE REFORMA AGRÁRIA NO NOROESTE MINEIRO - BRASIL
}

\section{Decentralization of the National Politics of ATER: an experience in the agrarian reform settlements in northwest mineiro - Brazil}

Suênia Cibeli Ramos de Almeida

Eng. Agrônoma da Embrapa Cerrados Analista de Pesquisa da Embrapa Cerrados

Planaltina/DF - Brasil suenia@cpac.embrapa.br

Marcelo Nascimento de Oliveira Eng. Agrônomo da Embrapa Cerrados Pesquisador da Embrapa Cerrados Planaltina/DF - Brasil manoli@cpac.embrapa.br

José Humberto Valadares Xavier Eng. Agrônomo da Embrapa Cerrados Analista de Pesquisa da Embrapa Cerrados

Planaltina/DF - Brasil jhumbert@cpac.embrapa.br

Artigo recebido para publicação em 17/06/2010 e aceito para publicação em 09/11/2010

RESUMO: $\quad$ A descentralização de políticas públicas no país permitiu a participação da sociedade civil organizada em diferentes âmbitos de sua formulação, execução e fiscalização. Desde a década de 1990, a universalização desse processo vem se consolidando no meio rural por meio da operacionalização de serviços de assistência técnica e extensão rural realizada por organizações não governamentais. Com a regulamentação da Política Nacional de Assistência Técnica e Extensão Rural, houve uma ampliação na participação das organizações sociais ligadas aos movimentos sociais de agricultores familiares. Este texto aborda uma experiência vivenciada por agentes de desenvolvimento em assentamentos de reforma agrária do município de Unaí, Minas Gerais.

Palavras chaves: Desenvolvimento local. Descentralização. Assistência técnica. Extensão rural. Agricultura familiar. Reforma agrária.

ABSTRACT: The citizen society participation in formulation, implementation and fiscalization of the public politics was granted to decentralization. The universalization of this process has been reinforcing by way of the technical assistance and rural extension services operates by NGO - Non-governmental organization since the decade 1990. Farms social organization participation has been enlarging after the Rural Extension and Technical Assistance National Politic regulation. This text presents one analyze about the experienced have lived by development agents in agrarian reform settlement in Unaí, Minas Gerais state.

Keywords: Local development. Decentralization. Technical assistance. Rural extension. Familiar agriculture. Agrarian reform. 


\section{INTRODUÇÃO}

Este texto trata da gestão, por parte de agentes de desenvolvimento local, de ações de assessoria técnica no contexto de um projeto de capacitação na perspectiva da Política Nacional de Assistência Técnica e Extensão Rural (Pnater) (BRASIL, 2004; BRASIL, 2008) como uma experiência de descentralização de serviços de assistência técnica e extensão rural de agricultores familiares nos assentamentos de reforma agrária, no noroeste mineiro, no município de Unaí. Esse projeto foi uma iniciativa do Sindicato dos Trabalhadores Rurais (STR) financiado pelo Ministério do Desenvolvimento Agrário (MDA) e com o apoio técnico da Empresa Brasileira de Pesquisa Agropecuária (Embrapa).

O projeto denominado "Capacitação de agentes de desenvolvimento e produtores para promover o desenvolvimento sustentável da agricultura familiar no município de Unaí - Minas Gerais" realizou-se no período de 2006 a 2008, pelo STR e Embrapa Cerrados em parceria com a Fundação Universitária de Brasília (Fubra) e as organizações locais dos agricultores familiares. Teve como objetivo capacitar técnicos assentados da reforma agrária e suas organizações para protagonizarem a melhoria da qualidade de vida das comunidades, por meio da utilização de métodos participativos de apoio ao desenvolvimento sustentável.

A capacitação consistiu na apropriação de dispositivos metodológicos participativos (ação-reflexãoação), visando ao planejamento, elaboração, execução, monitoramento e avaliação de planos de ação, em 19 assentamentos/comunidades da agricultura familiar com foco numa interação dialógica. A equipe de agentes de desenvolvimento foi formada por 11 filhos de agricultores, assentados da reforma agrária, técnicos em agropecuária e desenvolvimento sustentável. Um dos objetivos desse grupo local de técnicos foi gestar uma cooperativa de assessoria técnica, capaz de apoiar o desenvolvimento dos assentamentos/comunidades, exercendo os princípios do diálogo, participação e protagonismo dos agricultores.

Este artigo propõe, entre outras coisas, uma leitura acerca da experiência vivenciada por esse grupo de filhos de agricultores na tentativa de acessar a operacionalização local do apoio e assessoria técnica aos assentados da reforma agrária por meio da Pnater no município de Unaí.

O texto estrutura-se em três momentos. No primeiro, contextualiza-se o debate que propiciou a democratização das instituições e das políticas públicas do Estado brasileiro; no segundo, apresenta-se uma periodização sobre os serviços de assistência técnica e extensão rural e suas mutações até a nova institucionalidade; no terceiro, aborda-se a experiência local dos agentes de desenvolvimento e, com base em algumas leituras teóricas, uma análise sobre os limites e caminhos dessa nova prática.

\section{DOS PROCESSOS DE DESCENTRALIZAÇÃO E PARTICIPAÇÃO SOCIAL}

De acordo com Nogueira (1997), a Constituição de 1988 foi determinante na legitimação da descentralização, definida não apenas como um novo tipo de arranjo federativo, mas também transferindo decisões, funções e recursos do executivo federal para os Estados e municípios. O novo arcabouço constitucional configurou uma descentralização de natureza política, na medida em que expressou as necessidades dos cidadãos e garantiu dispositivos de participação da sociedade. Dessa forma, apresentou-se não somente como uma descentralização meramente técnica, fiscal ou administrativa.

Para que essa mutação de natureza política pudesse ser operacionalizada no âmbito do Estado e da prestação de seus serviços, seria necessário instituir significativas mudanças para alcançar essa intencionalidade. Com um histórico político cultural patrimonialista e a experiência de governos ditatoriais, esse processo não se estabeleceria simplesmente por via de novos ordenamentos jurídicos.

Como afirma Nogueira (1997), ainda que exista relação positiva entre democracia e descentralização, a gestão democrática do sistema não está centrada apenas na grande eficácia atribuída à gestão colegiada e à administração. Essa definição de descentralização opera com uma visão tecnocrática que ignora a necessária mudança na correlação de forças que o movimento descentralizador deve gerar, além de omitir a existência de projetos hegemônicos no poder e a necessidade de gestar alternativas de mudança. 
É importante ressaltar que esse tipo de compreensão corre o risco de não chegar a distinguir a natureza dos processos políticos que dão origem à mudança. Isso porque não se pode perder de vista que a democracia é um sistema político que se caracteriza por sustentar uma lógica expansiva da esfera pública, em que a tomada de decisões tende progressivamente a ser feita no espaço público (TOBAR, 1991).

As políticas públicas direcionadas ao campo, particularmente, a Pnater, voltada para a agricultura familiar, representaram um marco desse deslocamento. Desde a década de 1970, os serviços de Assistência Técnica e Extensão Rural (Ater) foram juntamente com o crédito agrícola, estruturantes para o avanço do capital no campo, especialmente, na época da "modernização conservadora", no contexto da agricultura patronal e do agronegócio.

A iniciativa em tela engloba, entre outras ações, as de assessoria técnica e capacitação de técnicos, agricultores e estudantes inseridos no mundo da agricultura familiar. A complexidade e diversidade social que abrange às agriculturas de base familiar exigem que essa política se caracterize pela flexibilidade e sensibilidade para adequar-se às inovações decorrentes da estrutura social, cultural, econômica, política e ambiental desses atores.

Há um processo em curso preconizado pela Pnater que diz respeito a uma inovação institucional baseada na descentralização que pressupõe o envolvimento dos atores locais nas decisões políticas e na operacionalização nos territórios dos serviços de Ater. Essa inovação vem na direção de caminhos já percorridos por outras políticas no país, especialmente, nas áreas de saúde e seguridade social.

O debate sobre a descentralização do Estado não é novo e, dependendo do foco de análise, nasce com o sistema do Estado moderno e a definição de Estado unitário ou federado. No contexto atual, a discussão investe-se de duas dimensões, a primeira vista, contraditória, mas que fazem parte de uma mesma dinâmica: a centralização e a descentralização.

A primeira diz respeito à diminuição da presença do Estado, seja como empreendedor, seja como prestador de serviços, determinada pela crise do Welfare State, nos países de capitalismo central, e do desmonte do Estado do nacional desenvolvimen- tismo, naqueles países de capitalismo periférico que ainda o cultivavam.

Como afirma Tobar (1991), as teses descentralizadoras iniciam-se com maior ênfase na década de 1980, patrocinada, especialmente, pelos organismos internacionais (ONU, World Bank). Essas instituições passam a defender a descentralização por entenderem que ela seria capaz, entre outras funções, de diminuir os efeitos negativos da burocracia; respeitar prioridades e necessidades locais; facilitar maior representatividade na formulação de decisões e equidade na alocação de recursos, aumentando a legitimidade e estabilidade institucional.

A segunda dimensão corresponde à pressão crescente da sociedade civil organizada por democracia e participação na formulação, execução e controle das políticas sociais, em especial, nos países que vivenciaram ditaduras prolongadas. Segundo Tobar (1991), alguns críticos desse processo acreditavam que essa descentralização poderia estar sob controle das elites tradicionais, tornando-a muito mais uma "concessão" à participação desses segmentos.

Esse autor alerta para a concepção que permeia esse pensamento, pois não está "associada a uma nova e mais ampla cidadania" e sim, "a uma reestruturação da hegemonia abalada pela política de ajuste que aumenta a dívida social, impedindo ou reduzindo a redistribuição de benefícios socais" (TOBAR, 1991, p. 10).

Sob o ponto de vista da redução do gasto público por meio de ajustes fiscais, as teses descentralistas começaram a tomar força quando enfatizada as funções econômicas ligadas a essa diminuição. Algumas tentativas foram realizadas no país na década de 1980, com parcos resultados, e, com maior ênfase, na década de 1990, com resultados mais comprometedores para a ação do Estado. Nesse último período, privatizações, terceirizações e desregulamentações compuseram os meios para o alcance dessa estratégia.

Nessa acepção de redução de gastos públicos, a "descentralização tem status de 'meio'(tático e estratégico) para o alcance de determinados fins". Por um lado, o conceito de descentralização foi esboçado como ferramenta para a expansão e intensificação da democracia. Por outro lado, foi pensado também como mecanismo de controle e dominação. Por esse motivo, 
a descentralização é concebida como processo dual, imprimindo novas racionalidades e legitimidade à ação do Estado (TOBAR, 1991).

Esse movimento descentralizador das políticas sociais para as esferas locais vem acompanhado de uma tendência à concentração cada vez maior do poder econômico do capital monopolista e da intermediação dos conflitos sociais que produz a multiplicação das instâncias de negociação e, portanto, de conciliações (TOBAR, 1991).

Nesse sentido, o estatuto de intermediação que caracteriza o processo descentralizador não é outra coisa senão a intermediação dos conflitos sociais. Portanto, existem diferentes maneiras de instrumentalizar o conceito, que, por sua vez, está relacionado aos distintos atores que fazem parte do conflito. Tobar (1991) adverte também que essa estratégia pode conduzir à fragmentação das demandas sociais, perdendo-se de vista o caráter global, nacional e internacional, do processo que produz essas desigualdades.

Outro espaço em que ressurge, frequentemente, a discussão acerca da centralização e descentralização é o debate sobre modelos de desenvolvimento. Os adeptos do processo centralizador baseiam-se em elementos de "eficiência" e "eficácia" no uso de recursos. Os defensores do processo descentralizador elegem o critério de "equidade" como o mais relevante, principalmente, para favorecer o compartilhamento espacial do poder e o processo político. Para tanto, são relevantes aspectos como o fortalecimento da esfera local que exprime o caráter eminentemente político dos processos descentralizadores, enquanto elementos como eficácia e eficiência reduzem esse ao campo administrativo.

A descentralização tende a ser vista como um processo mais amplo de reforma social, na medida em que implica redistribuição de poder tanto na tomada de decisões quanto na operacionalização. Tobar (1991) chama a atenção para a condição básica no alcance da autoridade local que reside na autonomia, na mesma medida que a soberania é componente fundante da autoridade nacional. É no surgimento dessas novas autonomias que se permite a distribuição do poder e o desenvolvimento da autonomia local por intermédio da participação popular e do controle social.

Um olhar sobre a experiência brasileira no que concerne ao problema da dicotomia entre centralização e descentralização aponta a Constituição Federal de 1988 como um marco divisor desse processo. Com um histórico de experiência de Estado centralizador, especialmente durante o período militar (1964-1985), no qual se configurou quase como um Estado unitário, os membros federados gozavam de uma autonomia fictícia, com escassa autonomia fiscal, uma vez que os principais tributos concentravam-se nas mãos do Executivo federal. Do ponto de vista político, a restrição democrática era ainda maior, com a indicação pela cúpula militar de governadores e prefeitos das maiores e principais cidades do país (ARRETCHE, 1999).

A experiência de transição democrática no Brasil caracterizou-se como um dos mais longos das experiências ditatoriais da América Latina. Esse hiato temporal foi possibilitado pelo arranjo político e institucional que o regime ditatorial instituiu. No espaço político, por meio do funcionamento, ainda que débil, de uma democracia representativa com a ação de um Congresso Nacional e um Sistema Judiciário limitados e a realização de eleições periódicas, favorecendo a sensação de "normalidade" dessas instituições (KINZO, 2001).

Contribuiu, também, para reforçar essa ideia de normalidade democrática, o êxito da economia, expressa por meio de altos índices de crescimento econômico e investimentos. Isso permitiu a consolidação de um Estado forte e empreendedor mesmo que, ao final desse período, o país experimentasse um processo de recessão intensa. Foram esses mecanismos que permitiram ao país vivenciar a experiência de um Estado fortemente centralizado em quase todos os aspectos da vida nacional.

De acordo com Souza (2001), a institucionalização do processo democrático na Constituição de 1988 se deu por duas vias: a abertura para a participação popular e a descentralização tributária para Estados e municípios. Esse processo possibilitou um novo federalismo apoiado na democracia. A introdução da descentralização assentava-se no argumento da eficiência e na promoção da democracia, na perspectiva, a princípio, de tornar os membros da federação politicamente autônomos.

Essa ponderação é importante na medida em que há fatores que limitam a plenitude desse processo, 
tais como a estrutura econômica, social, política e a capacidade administrativa dos Estados e municípios. Essa não é uma constatação nova, pois, em um estudo comparativo dos níveis de descentralização em 45 países, realizado por Vieira (1971), mostrou-se que o grau de descentralização em um país depende principalmente do desenvolvimento de seus recursos econômicos e tecnológicos e não dos elementos e das características da organização constitucional.

Em que pese esses limites, são notáveis os avanços da descentralização do Estado brasileiro, no que diz respeito ao sistema de proteção social, formulado na década dos 1960 e 1970. Arretche (1999), analisando o sistema de proteção social, afirma que houve de fato um processo de descentralização desse sistema por meio da redefinição de atribuições e competências dos atores envolvidos. Para essa autora, isso decorre do legado das políticas, do regramento constitucional e infraconstitucional à disposição e da própria engenharia operacional de cada política social. Assim, não há fatores determinantes a priori, cada política terá que instituir suas estruturas de funcionamento, e os atores inseridos nesse processo têm papel preponderante.

\section{O LEGADO DA ATER}

A assistência técnica e extensão rural não é propriamente uma política social, mas sim, uma política pública de apoio ao desenvolvimento. Ao considerarmos a história da extensão rural pública no Brasil como o legado prévio a que se refere Arretche (1999), pode-se esquematizá-la em seis momentos demarcados, resultado da configuração das políticas governamentais para o setor, bem como do contexto histórico.

Para uma leitura linear da história da ATER no Brasil, proponho a seguinte esquematização: i) criação; ii) expansão; iii) estatização; iv) desestruturação; v) descentralização e vi) novas institucionalidades.

$O$ legado da ATER inicia com a primeira experiência no Estado de Minas Gerais com a criação da Associação de Crédito e Assistência Rural (ACAR), aliando crédito rural e tecnologia baseada no enfoque difusionista e na perspectiva de superação do "atraso" do setor. Com a penetração do capitalismo no campo, os serviços de assistência técnica e extensão rural se espraiaram e, em 1956, foi criada a Associação Brasileira de Crédito e Assistência Rural (ABCAR).

A grande expansão e a estruturação nacional dos serviços de ATER tornaram-se realidade com os governos militares, em especial, na gestão Geisel, no contexto da instituição dos programas especiais para a abertura de novas fronteiras agrícolas na região dos cerrados no Centro-Oeste e na Amazônia. Em 1973, foi constituída a Empresa Brasileira de Assistência Técnica e Extensão Rural (Embrater), que significou a estatização de parcela considerável desses serviços. É importante ressaltar que esse crescimento foi favorecido pela conjuntura da época na qual o Estado se constituiu como o grande empreendedor e financiador dos avanços capitalistas não apenas no campo como também na indústria, especialmente de base.

A crise do "Milagre brasileiro" também atingiu esses serviços e as concessões de crédito que estruturavam as ações de assistência técnica e extensão rural. Na década de 1980, registrou-se uma nova crise do capitalismo e o retorno das teses liberais que propugnavam a retirada do Estado tanto de empreendimentos quanto da prestação de serviços. Assim, na entrada da década de 1990, assistiu-se a desestruturação de vários setores antes ligados ao Estado, inclusive, a extinção da Embrater.

A partir desse momento, o espaço de ação estaria aberto às iniciativas de outros atores sociais, tanto aqueles ligados à estrutura federativa, como os Estados federados e as municipalidades, quanto às organizações não governamentais. O próprio governo federal por meio do Instituto Nacional de Colonização e Reforma Agrária (Incra ) gestou uma alternativa de assistência técnica aos assentados da Reforma Agrária, o Lumiar.

Com a abertura do período do governo Lula, ressurge com força o debate sobre uma "Nova Extensão Rural", desdobrando-se no desenho de uma política específica para o setor, a Política Nacional de Assistência Técnica e Extensão Rural (Pnater). Inicia-se também a discussão à respeito de novas institucionalidades, novos perfis profissionais, nova matriz tecnológica, entre outros aspectos, que seriam estruturadores para essa política. 
A descentralização desses serviços torna-se um dos principais eixos, permitindo que diversos atores sociais participem desse espaço. De acordo com o Quadro 1, que consta do manual operacional de ATER, do ponto de vista da proposição de descentralização, a participação social se dá essencialmente pela representação dos agricultores por suas organizações nos espaços formais dos fóruns nacionais e estaduais estabelecidos para o âmbito das decisões políticas.

A operacionalização dessa política, no âmbito local, é realizada por técnicos por intermédio das equipes de articulação e dos núcleos operacionais que podem ter relações com o lugar ou não. Dos critérios utilizados para a escolha desses profissionais, o que pode ser considerado, muito forçosamente, como aproximativo de pertencimento ao lugar é a exigência de experiência na região. das realidades dos lugares e dialogar com os princípios da descentralização dessa opção como flexibilidade, gradualismo, progressividade, transparência e mecanismos de controle social (TOBAR, 1991).

Entretanto, como salientado por Nogueira (1997), há que se atentar para não confundir descentralização, democratização e participação, como se a descentralização contivesse em si mesma o impulso necessário para frear o autoritarismo, democratizar a sociedade e ampliar a participação dos cidadãos. Para esse autor, a participação não se descentraliza. Ela existe ou não no processo, não cabendo ao órgão central concedê-la ou delegá-la. O que ela permite é uma melhor canalização ou vocalização das demandas sociais da população, mas isso só ocorre em comunidades que estão mobilizadas na defesa de seus interesses.

\begin{tabular}{|c|c|}
\hline Instâncias de Coordenação e Supervisão \\
\hline • Incra \\
• & Diretoria de Desenvolvimento de Projetos de Assentamento - DD \\
\hline Instâncias de Participação Social \\
\hline O Fórum Nacional de ATES \\
• O Fórum Estadual de ATES \\
\hline Instâncias de Execução Técnica \\
\hline$\quad$ Equipes de Articulação \\
- Núcleos Operacionais
\end{tabular}

Quadro 1: Estrutura de coordenação, gestão, execução e participação social.

Fonte: Ministério do Desenvolvimento Agrário (BRASIL, 2008, p. 19).

A constituição desses fóruns pode ser considerada uma descentralização, no entanto ela não significa uma redistribuição do poder na perspectiva de uma transferência na alocação das decisões para o nível local (TOBAR, 1991). O que se percebe é a persistência de um espaço de poder centralizado por meio das representações das confederações e federações, de direções nacionais de movimentos sociais organizados e de organizações não governamentais, onde a força dos lugares, dos espaços locais, tem ressonância pouco expressiva. Esse tipo de descentralização caracterizase como um deslocamento de conflito.

Em um país com dimensões continentais como o Brasil, uma democratização significativa deveria basear-se na distribuição do poder no âmbito das localidades, pois permitiria expressar a diversidade
A operação de descentralização resulta em poucos ganhos de escala imediata - seja no campo específico da melhoria da gestão pública, seja no que se refere ao fortalecimento das organizações "civis", por isso o risco de desmobilização e retrocesso no movimento de cidadania cresce expressivamente (NOGUEIRA, 1997).

\section{ENVOLVIMENTO DOS ATORES LOCAIS: RE- ALIDADE OU UMA ARMADILHA?}

A experiência da reforma agrária no Brasil e, em especial, de assistência técnica nesses espaços é recente e marcada pela fragilidade tanto do ponto de vista de sua infraestrutura quanto da oferta de serviços 
aos assentados. No município de Unaí/MG, local que abriga parcela considerável dos assentamentos desse Estado, as condições são bastante similares ao restante do país, com acesso restrito aos serviços de assistência técnica oficial.

Novas modalidades de capacitação profissional para agricultores e técnicos na perspectiva de mudança de atitude desses profissionais foram concebidas e apoiadas pelo Estado, fortalecendo um processo já em curso com a constituição de cursos de alternância direcionados para filhos de agricultores e para os agricultores familiares.

No caso específico do município de Unaí, a formação desses agentes de desenvolvimento para atuação na assessoria técnica aos agricultores familiares foi possibilitada pelo curso profissionalizante técnico em agropecuária e desenvolvimento sustentável, realizado na Escola Agrícola de Unaí, no período de 2003 a 2006, e teve como princípios formativos a alternância, a formação em processo, tendo a prática cotidiana como elemento fundamental para o aprendizado, a educação integral e continuada.

O currículo foi organizado para promover a integração entre as ações do tempo na escola e do tempo na comunidade, a alternância, buscando, sempre que possível, fazer as conexões entre os conteúdos e as situações vividas pelos alunos no seu cotidiano agrícola. O objetivo do curso era formar um agente de desenvolvimento capaz de apoiar os agricultores familiares dos assentamentos tanto na dimensão produtiva, quanto nos aspectos sociais e econômicos, entendidos como indissociáveis no processo de desenvolvimento.

O curso de alternância na escola agrícola de Unaí para formação de técnicos em agropecuária e desenvolvimento sustentável, na medida em que participava filhos de agricultores, assentados da reforma agrária, visava suprir a lacuna de oferecimento de serviços de assistência técnica.

Participaram do curso, também, as organizações, como Sindicato dos Trabalhadores Rurais (STR) de Unaí, que discutiam os desdobramentos dessa qualificação para reverter em valorização profissional dos filhos dos agricultores e, ao mesmo tempo, melhorar as atividades na agricultura, por meio de inovações técnicas e sociais adaptadas e apropriadas àquelas condições. Ademais, esses agentes poderiam aportar um novo perfil no saber/fazer/agir de agentes de desenvolvimento na perspectiva da "Nova Extensão Rural", na medida em que dialogavam com o lócus de aprendizagem real.

O Sindicato de Trabalhadores Rurais de Unaí, em parceria com a Embrapa, elaborou um projeto financiado pelo MDA, para a capacitação em meio real desses técnicos e de agricultores familiares com aporte metodológico e com referências técnicas e sociais, tendo como referência o projeto de $\mathrm{P} \& \mathrm{D}$, denominado Projeto Unaí (XAVIER et al., 2009).

OProjeto Unaí foi desenvolvido pela Empresa Brasileira de Pesquisa Agropecuária (Embrapa), em parceria com diversas instituições de pesquisa, ensino e instituições locais, iniciado em 2002 e finalizado em 2008. Tinha como objetivo apoiar o desenvolvimento da agricultura familiar por meio do desenvolvimento de referências técnicas e sociais.

O projeto financiado pelo MDA intencionou ser o lócus para a aprendizagem de novos saberes e, ao mesmo tempo, transformar-se no espaço para a materialização de uma organização, a cooperativa de assessoria técnica para os assentados da reforma agrária, denominada Cooperativa de Assessoria Técnica para o Desenvolvimento Sustentável (COOPATEC), cujo projeto inicial fora esboçado por ocasião da vivência na própria escola agrícola. A proposta de constituição desse espaço de trabalho comungava com a proposição da Pnater em criar condições para a descentralização desses serviços, bem como para a democratização no exercício dessa política pelas próprias organizações locais dos agricultores.

A experiência de qualificação de agentes de desenvolvimento consistiu na apropriação de dispositivos metodológicos participativos, visando ao planejamento, elaboração, execução, monitoramento e avaliação de planos de ação em 19 assentamentos/comunidades da agricultura familiar com foco numa interação dialógica, objetivando o apoio ao desenvolvimento.

A equipe de agentes de desenvolvimento foi formada por 11 filhos de agricultores, assentados da reforma agrária, técnicos em agropecuária e desenvolvimento sustentável. Os desdobramentos dessas ações representaram um novo espaço de discussão das organizações. Ao se depararem com um amplo diag- 
nóstico da situação dos assentamentos, em especial, das condições precárias de infraestrutura, puderam constituir uma ação coletiva e pressionar a municipalidade para a resolução do problema das estradas de difícil acesso e sem manutenção.

Do ponto de vista da organização da produção, apesar das similaridades das situações, cada realidade determinou ações pontuais, como a aquisição de tanques de resfriamento de leite ou a melhoria do processo de cultivo, sem maiores impactos para o conjunto da agricultura familiar que vivencia a experiência de viabilizar-se no campo.

Como assinalado por Almeida et al. (2008), apesar do esforço de formação na perspectiva de não dissociar inovações técnicas de inovações sociais, mesmo quando as maiores fragilidades dos assentados concentram-se nos aspectos organizativos, os agentes de desenvolvimento não conseguiram superar essa dicotomia, e a concentração de ações nos aspectos produtivos predominou, demonstrando que a realidade impõe sua história cultural e social.

A experiência permaneceu em funcionamento durante 18 meses, nos quais os agentes tentaram viabilizar institucionalmente a cooperativa para a continuidade do trabalho de apoio ao desenvolvimento, posto que a ausência da assessoria técnica aos assentados foi e é identificada como uma das principais fragilidades para o acesso a processos de inovações sociais e crédito agrícola - elementos fundamentais para a consolidação e desenvolvimento dos assentamentos.

Mesmo reconhecendo esse fato, a burocracia, seja estatal ou corporativa, foi incapaz de constituir procedimentos flexíveis para comportar a diversidade de situações e condições para viabilizar o processo de descentralização e participação dos atores locais, fatores imprescindíveis para desencadear dinâmicas inclusivas.

A iniciativa da cooperativa não foi reconhecida por não responder aos critérios de elegibilidade exigidas para o cadastramento de instituições de ATER (BRASIL, 2008). De certo que, nas realidades em que se encontram os assentamentos de reforma agrária e suas organizações, há necessidade de refletir sobre novas institucionalidades.

Uma nova institucionalidade deveria acolher as experiências dos atores que compõem o mosaico de suas localidades com exigências que expressem a complexidade dessas vivências e não apenas a idealidade. Isso porque as decisões, as estruturas e mecanismos para a institucionalização da Pnater constituem-se de espaços ainda centralizados, representados por meio de instâncias de coordenação e supervisão nacional e estaduais; de fóruns nacional e estaduais para a participação social e, na execução, de equipes técnicas de articulação e dos núcleos operacionais (BRASIL, 2008).

Essa estrutura, ainda que comporte a participação de entidades da sociedade civil organizada, não possibilita expressar a riqueza da diversidade dos lugares, pois, muitas vezes, entidades de representação centralizadas expressam interesses corporativos sem diálogo com os atores locais.

A atualidade no Brasil, com a criação de inovações sociais em todos os campos da vivência, particularmente na educação e nos experimentos sociais, exige uma postura/atitude menos dogmática, mais aberta às inovações da sociedade. A padronização de critérios, como no caso em particular, da exigência de comprovação de experiência, expressa em anos de atividade no exercício da profissão, sem considerar outros aspectos também importantes, como, por exemplo, os laços de pertencimento ao lugar, muitas vezes desqualifica atores locais, corresponsáveis por essa experiência de reforma social na estrutura fundiária do país, historicamente excludente.

\section{CONSIDERAÇÕES: A CIDADANIA ENCUR- RALADA}

Dois aspectos sobre essa iniciativa se mostraram relevantes no decorrer do processo. $\mathrm{O}$ primeiro diz respeito aos limites da "vontade de mudar", mesmo quando a centralidade da ação era romper com a intervenção disciplinar e impositiva que caracterizou a extensão tradicional. Embora essa prática não esteja institucionalizada, ela constitui-se um fazer instituído, influenciando as relações sociais impregnadas de crenças, conceitos e experiências.

O segundo relaciona-se com a busca da valorização das iniciativas locais, que objetivava dar visibilidade e potencialidade a tentativa de novas 
institucionalidades por meio da criação da cooperativa de assessoria técnica. Tentava-se, assim, dialogar com os pressupostos da Pnater de descentralização desses serviços, gerando saberes, fazeres, trabalho e renda no município.

Os procedimentos para o reconhecimento das iniciativas populares são paralisados pela burocracia que espelham uma temporalidade diferente das intencionalidades dos programas, projetos e políticas desenhadas em processos de amadurecimento democráticos que caracterizam o momento atual da vivência política do país.

Uma tentativa para compreender esses movimentos está na interpretação de Carvalho (2007) sobre a formação do cidadão no Brasil. Segundo esse autor, o peso da herança colonial escravista e latifundiária e da cultura política paternalista e coronelista ainda produz efeitos significativos que impossibilitam o exercício da cidadania ativa. Com um longo histórico de "direitos civis e políticos tão precários", a ação organizada para a conquista de direitos sociais, que garantem a participação e acesso a riqueza do país, fica prejudicada.

Para Carvalho (2007), o percurso para a constituição da cidadania no país foi invertido quando comparado com a experiência histórica de outras nações ocidentais, especialmente o caso inglês, que conquistou primeiro os direitos civis e, na sequência, os políticos e sociais. Assim expressa o autor:

A antecipação dos direitos sociais [faz] com que os direitos não [sejam] vistos como tais, como independentes da ação do governo, mas como um fator em troca do qual se [deva] gratidão e lealdade. A cidadania que dai [resulta é] passiva e receptora antes que ativa e reivindicadora (CARVALHO, 2007, p. 126).

Compartilhando dessa compreensão, considera-se que essa herança afetou a sociedade brasileira, posto que o desenvolvimento da consciência de direitos é um processo relacional, necessitando do exercício dos sujeitos e das instituições. Nessa direção e no contexto de possibilidades vivenciado pela nossa so- ciabilidade, não se pode esquecer dos condicionantes da experiência histórica na constituição da cidadania no país. Isso porque a descentralização das políticas públicas está diretamente relacionada com a forma de inserção social dos atores envolvidos. Isso não significa que estamos eternizados numa "semicidadania" que, para se expressar, necessita de autorização.

Nesse sentido, corroboramos a compreensão de Santos (2002), segundo esse autor, vivenciamos uma fase transitória no que diz respeito aos paradigmas científicos e, por esse motivo, a exigência de olhar o mundo das relações sociais sob novo prisma exige uma mudança nos procedimentos. Uma dessas possibilidades seria por meio da "sociologia das ausências" e das "sociologias das emergências". A primeira diz respeito a um tipo de:

...investigação que visa demonstrar que o que não existe é, na verdade, activamente produzido como tal, isto é, como uma alternativa não-credivel ao que existe. ...O objectivo da sociologia das ausências é transformar objectos impossiveis em possiveis e com base neles transformar as ausências em presenças. (SANTOS, 2002, p. 246).

De acordo com o autor, isso se torna necessário visto que há um processo de deslegitimação e desvalorização das experiências locais portadoras de possibilidades de mudanças realizado pelas lógicas dominantes no campo da ciência, a fim de não as considerar alternativas às iniciativas hegemônicas. $\mathrm{O}$ autor identifica cinco lógicas ou formas de produção da não-existência ou desvalorização das experiências locais: a monocultura do saber e do rigor do saber - as únicas ciências portadoras de conhecimentos seriam a ciência moderna e a alta cultura; a monocultura do tempo linear - considerado como evolutivo, tais como progresso, modernização, desenvolvimento, entre outros; a lógica da classificação social baseada na monocultura da naturalização das diferenças; a lógica da escala dominante - o universalismo é a escala que detêm legitimidade sobre o particular e o local e a lógica produtivista.

Santos (2002) ressalta ainda que a ciência hegemônica instituiu várias formas de silêncio para suprimir e marginalizar as outras formas de saberes 
que acabam não emergindo e estruturando outras formas de estar no mundo. Assim, pode-se concluir que a sociologia das ausências, ao permitir que outras vozes sejam pronunciadas, torna-as ouvidas e visíveis.

$\mathrm{O}$ autor considera que o mundo guarda três dimensões importantes e profundamente vivida e sentida pelos homens, quais sejam, a realidade, a necessidade e a possibilidade. Dessa forma, ele situa a outra forma de conceber conhecimento por intermédio da sociologia das emergências, essa:

..é a investigação das alternativas que cabem no horizonte das possibilidades concretas.... Em cada momento, há um horizonte limitado de possibilidades e por isso é importante não desperdiçar a oportunidade única de uma transformação especifica que o presente oferece: carpe diem. (SANTOS, 2002, p. 255).

Nesse sentido, o regramento para os processos de descentralização que permeiam as políticas públicas no Brasil, embora universalizante e condicionado por um passado centralizador e inibidor da cidadania, necessita expressar também as peculiaridades dos lugares, só assim poderá contribuir para inserir populações historicamente excluídas.

\section{REFERÊNCIAS}

ALMEIDA, S. C. R.; DANSA, C.; MOLINA, M. C.; XAVIER, J.H.V; SCOPEL, E.; ZOBY, J. L. F. A inserção dos técnicos formados pelo curso CTADS no apoio ao desenvolvimento local em Unaí: ensinamentos e perspectivas. In: ENCONTRO DA REDE DE ESTUDOS RURAIS: TECENDO O INTERCÂMBIO DIVERSIDADE E PERSPECTIVAS DO MUNDO RURAL NO BRASIL CONTEMPORÂNEO, 3., 2008, Campina Grande. Anais... Campina Grande-PB: UFCG, 2008.

ARRETCHE, M. T. Políticas sociais no Brasil: descentralização em um Estado federativo. Revista Brasileira de Ciências Sociais, v. 14, n. 40, p. 111-141, 1999.

CARVALHO, J. M. de. Cidadania no Brasil: o longo caminho. 9. ed. Rio de Janeiro: Civilização Brasileira, 2007.
KINZO, M. D. G. A democratização brasileira: um balanço do processo político desde a transição. São Paulo em Perspectiva, v. 15, n. 4, p. 3-12, 2001.

tBRASIL. Ministério do Desenvolvimento Agrário. Secretaria da Agricultura Familiar. Departamento de Assistência Técnica e Extensão Rural. Politica Nacional de Assistência Técnica e Extensão Rural. Brasília: MDA, 2004.

Ministério do Desenvolvimento Agrário. Secretaria da Agricultura Familiar. Departamento de Assistência Técnica e Extensão Rural. Política Nacional de Assistência Técnica e Extensão Rural. Brasília. MDA, 2008.

NOGUEIRA, M. A. A dimensão política da descentralização participativa. São Paulo em Perspectiva, v. 11, n. 3; p. 8-19, 1997.

SANTOS, B. S. Para uma sociologia das ausências e uma sociologia das emergências. Revista Crítica de Ciências Sociais, v. 63, p. 237-280, 2002.

SOUZA, C. Federalismo e descentralização na Constituição de 1988: processo decisório, conflitos e alianças. Dados - Revista de Ciências Sociais, Rio de Janeiro, v. 44, n. 3, p.513-560, 2001.

TOBAR, F. O conceito de descentralização: usos e abusos. Planejamento e políticas públicas, v. 5, p.3151, 1991.

VIEIRA, P. R.. Em busca de uma teoria da descentralização. FGV 2, Rio de Janeiro: [s.n.], 1971.

XAVIER, J. H. V.; OLIVEIRA, M. N.; GASTAL, M. L.; ROCHA, F. E. C.; SILVA, F. A. M.; SCOPEL, E. A experiência de desenvolvimento sustentável do Projeto Unaí: pesquisa e inclusão social em assentamentos de reforma agrária. In: SOUSA, I. S. F.; CABRAL, J. R. F. Ciência como instrumento de inclusão social. Brasília: Embrapa Informação Tecnológica, 2009. p. 277-326. 